\title{
Avaliação clínica e citológica do conduto auditivo externo de cães com otite
}

\section{Clinical and cytological evaluation of the external ear canal of dogs with otitis}

\section{Avaliación clínica y citológica del conducto auditivo externo de perros con otitis}

\author{
Fernando Malagutti Cunha'; Selene Dall'Acqua Coutinho²; Antônio Matera³; Wagner Alexey Back \\ Fiorio ${ }^{4}$; Maria Christina Cristóvão Ramos ${ }^{4}$; Lúcia Maria Guedes Silveira ${ }^{5}$
}

Hospital Veterinário da Faculdade de Medicina Veterinária da Universidade Paulista, Campus Tremembé. São Paulo, SP, Brasil

\section{Resumo}

Objetivo: Estudar cães portadores de otite externa, buscando detectar fatores predisponentes e microrganismos envolvidos na etiopatogênese dessa afecção. Material e Método: Quarenta animais (30 com otite externa e 10 sem a doença) provenientes do Serviço de Clínica Médica do Hospital Veterinário da Faculdade de Medicina Veterinária da Universidade Paulista, São Paulo, SP, Brasil, foram submetidos a exame otológico físico prévio. Amostras de secreção ótica foram colhidas do conduto auditivo externo com escovas ginecológicas, procedendo-se posterior análise citológica nesses materiais, com auxílio de três técnicas distintas de coloração. Resultados: Dentre os pacientes com otite, encontraram-se $60 \%$ de cães com raça definida, $60 \%$ de fêmeas, $74 \%$ com idade igual ou superior aos quatro anos, $60 \%$ com pelagem curta e $80 \%$ com orelhas pendulares. O método de Gram mostrou-se eficaz na pesquisa de bactérias e fungos, e as técnicas de Papanicolaou e Rosenfeld mais adequadas à observação de células epiteliais, inflamatórias e eritrócitos. O microrganismo mais verificado nas extensões produzidas a partir de ouvidos doentes foi Malassezia sp $(63,3 \%)$. Conclusões: Os resultados indicam que dados colhidos na anamnese e no exame físico, aliados às informações fornecidas pelo estudo citológico de secreções óticas são eficientes para a caracterização de elementos relacionados à etiopatogênese da otite canina.

Palavras-chave: Otite externa, etiologia. Diagnóstico clínico. Condutos auditivos, citologia. Técnicas citológicas. Cães.

\footnotetext{
${ }^{1}$ Professor Adjunto de Clínica Médica e Terapêutica de Pequenos Animais - Universidade Paulista. CRMV-SP 9509

${ }^{2}$ Professora Titular de Microbiologia e Doenças Infecciosas - Universidade Paulista. CRMV-SP 2399

${ }^{3}$ Professor Titular de Patologia e Clínica Cirúrgica - Universidade Anhembi-Morumbi. CRMV-SP 0010

${ }^{4}$ Lab\&Vet - Consultoria e Diagnóstico Veterinário. CRMV-SP 7792, CRMV-SP 4936

${ }^{5}$ Professora Adjunta de Patologia e Clínica Cirúrgica - Universidade Paulista. CRMV-SP 8573
} 


\section{Introdução}

A otite externa representa uma das moléstias mais comuns e frustrantes na clínica médica de pequenos animais. Este fato pode ser atribuído ao elevado percentual de recidiva após suspensão da terapia, situação que está parcialmente relacionada à falta de precisão diagnóstica das causas fundamentais de tal processo patológico ${ }^{1-5}$. Por definição, o termo otite expressa a existência de processo inflamatório envolvendo tecidos de revestimento e estruturas associadas ao ouvido, sem especificar, entretanto, os fatores desencadeantes do evento ${ }^{1}$.

A análise citológica de secreções oriundas de ouvidos enfermos pode propiciar informações importantes sobre possíveis alterações histológicas ocorridas na região. Ela demonstra alto valor na detecção de células e microrganismos relacionados; representa procedimento auxiliar rápido, prático e de baixo custo, indicado em todos os casos de otite para investigação dos elementos incriminados ao desenvolvimento ou à perpetuação do mencionado distúrbio ${ }^{4,6,7}$.

Na presente pesquisa, amostras de secreções óticas colhidas de cães sadios e daqueles com otite foram microscopicamente estudadas para a busca de agentes microbianos e tipos celulares, objetivando correlacionar a existência de fatores predisponentes e achados citológicos à ocorrência da enfermidade.

\section{Material e Método}

\section{Animais}

Provenientes do Serviço de Clínica Médica do Hospital Veterinário da Faculdade de Medicina Veterinária da Universidade Paulista, São Paulo, SP, foram utilizados 40 cães de diferentes raças, com idade variada, machos ou fêmeas. Os cães foram identificados quanto ao tipo de pelagem (curta ou longa) e anatomia dos pavilhões auriculares (pendulares ou eretos). Os animais foram distribuídos em dois grupos distintos: 30 cães com otite bilateral ("grupo otite") e 10 cães não otopatas (grupo controle). Todos os indivíduos empre- gados foram selecionados mediante prévia anamnese e exame otológico-padrão.

\section{Material e Preparo de Lâminas}

Espécimes destinados ao exame citológico foram colhidos da porção horizontal do conduto auditivo externo com auxílio de escovas ginecológicas estéreis. As secreções obtidas sofreram extensão sobre lâminas para microscopia novas e desengorduradas. Utilizando-se corantes distintos, três lâminas com material oriundo de cada conduto avaliado foram preparadas para posterior análise, buscando-se, por meio desses procedimentos, a observação de microrganismos e/ou tipos celulares.

\section{Técnicas de Coloração}

Empregou-se o método de Gram para verificação da presença e estudo morfológico de agentes microbianos (bacterianos e/ou fúngicos), e as técnicas de Papanicolaou e Rosenfeld na pesquisa de células epiteliais, inflamatórias e eritrócitos.

\section{Resultados}

Dentre os 30 cães com otite, $60 \%(\mathrm{n}=18)$ apresentavam raça definida, com predomínio de Poodles, $21 \%$ $(n=6)$ e de Pastores-Alemães, 21\% $(n=6)$ (Figura 1).

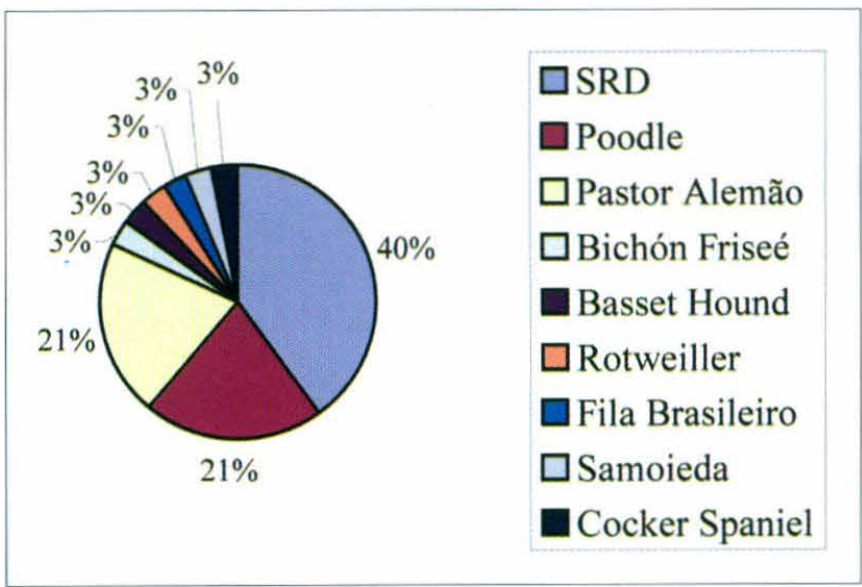

Figura 1 - Representação gráfica dos percentuais de cães afetados por otite externa atendidos junto ao serviço de Clínica Médica de Pequenos Animais da Faculdade de Veterinária da Universidade Paulista, segundo a raça. São Paulo, SP, 2004 


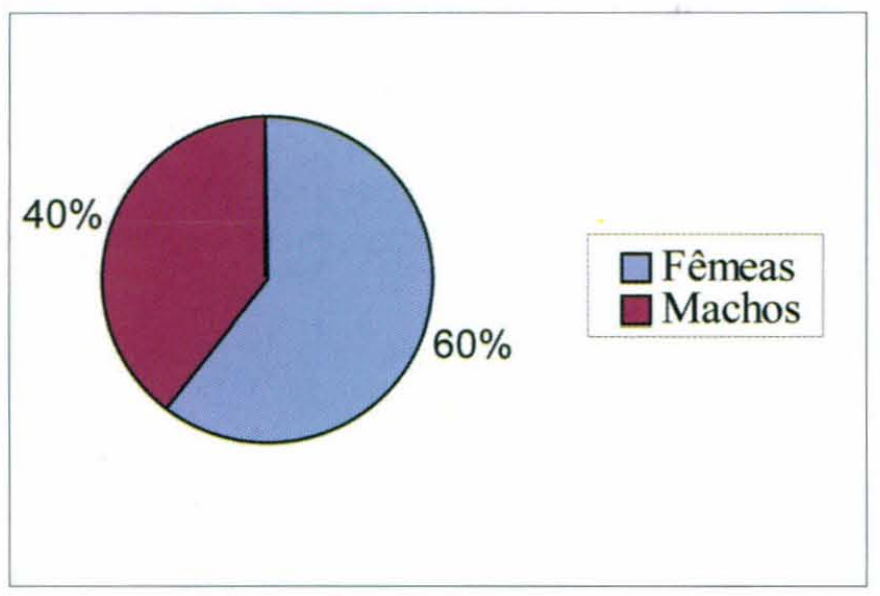

Figura 2 - Representação gráfica dos percentuais de cães afetados por otite externa atendidos junto ao serviço de Clínica Médica de Pequenos Animais da Faculdade de Veterinária da Universidade Paulista, segundo o sexo. São Paulo, SP, 2004

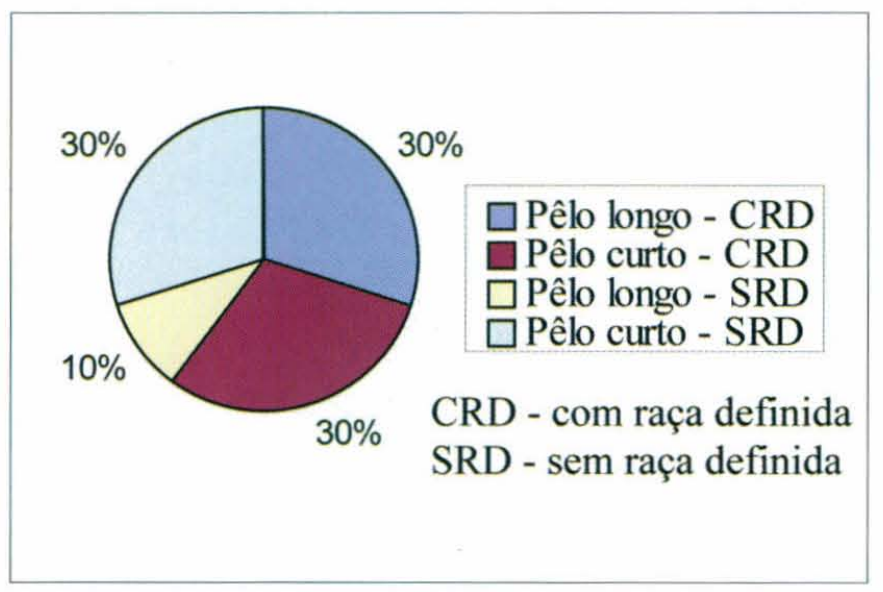

Figura 4 - Representação gráfica dos percentuais de cães afetados por otite externa atendidos junto ao serviço de Clínica Médica de Pequenos Animais da Faculdade de Veterinária da Universidade Paulista, segundo o comprimento da pelagem. São Paulo, SP, 2004

Dos animais acometidos 18 eram fêmeas e 12 eram machos, representando, respectivamente, $60 \%$ e $40 \%$ dos pacientes estudados (Figura 2). Mais de 70\% destes indivíduos tinham idade igual ou superior a quatro anos (Figura 3). A maior parcela de cães do grupo, exibia pêlos curtos $(60 \%)$ e orelhas pendulares $(80 \%)$ (Figuras 4 e 5).

Análises microscópicas procedidas em espécimes oriundos de cães afetados por otite por meio da técnica de Gram, revelaram presença de bactérias em forma

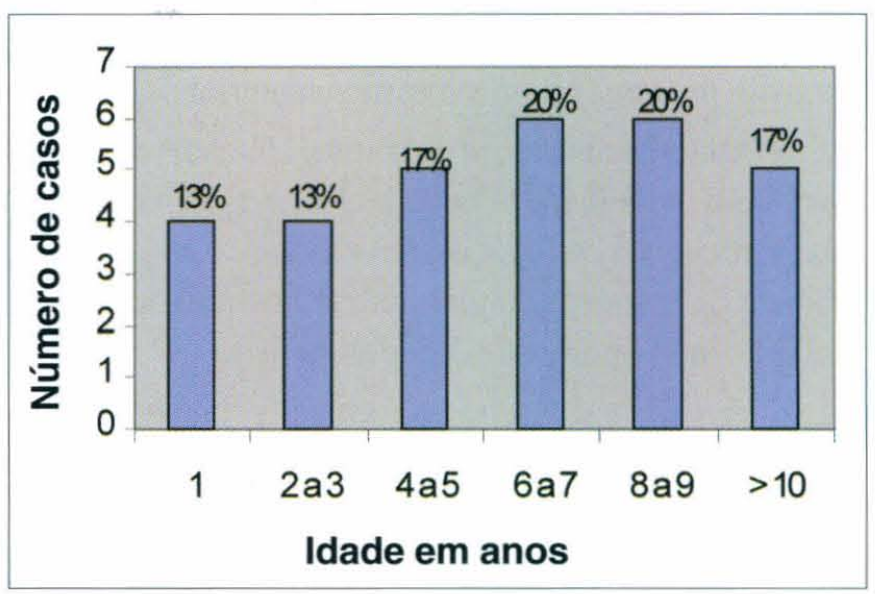

Figura 3 - Representação gráfica dos percentuais de cães afetados por otite externa atendidos junto ao serviço de Clínica Médica de Pequenos Animais da Faculdade de Veterinária da Universidade Paulista, segundo a faixa etária. São Paulo, SP, 2004

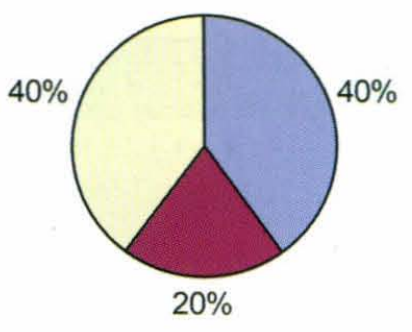

$\square$ Pavilhões auriculares pendulares (CRD)

Pavilhões auriculares eretos (CRD)

Pavilhões auriculares pendulares (SRD)

CRD - com raça definida $\mathrm{SRD}$ - sem raça definida

Figura 5 - Representação gráfica dos percentuais de cães afetados por otite externa atendidos junto ao serviço de Clínica Médica de Pequenos Animais da Faculdade de Veterinária da Universidade Paulista, segundo a anatomia dos pavilhões auriculares. São Paulo, SP, 2004

de cocos, Gram positivas, bem como bastonetes delicados dispostos em paliçada ou caracteres chineses, Gram positivos; bastonetes filamentosos, Gram negativos, também puderam ser observados. Células leveduriformes com brotamento único em base larga (Malassezia sp) foram detectadas como agentes únicos ou associados a bactérias. Estes microrganismos eram os mais freqüentemente verificados nas extensões provenientes de ouvidos enfermos, estando presentes em $63,3 \%$ dos casos (Tabela 1). Raras leveduras puderam ser constatadas em espécimes colhidos de con- 
dutos auditivos hígidos (grupo controle). Bactérias não estavam presentes nestes mesmos materiais.

Abundantes blocos de células epiteliais descamadas foram evidenciados pelas técnicas de Papanicolaou e Rosenfeld nos esfregaços derivados de cães com otite (Tabela 2). Escassas células epiteliais foram detectadas nas amostras obtidas de ouvidos sadios.

Verificou-se também neutrófilos contendo bactérias fagocitadas em associação a leucócitos mononucleares sugerindo existência de reação inflamatória mista em alguns casos de enfermidade ótica,

Tabela 1 - Percentual de extensões oriundas de cães com otite externa, segundo a presença de microrganismos corados através da técnica de Gram. São Paulo, SP, 2004

\begin{tabular}{lc}
\hline Microrganismos & Extensões $(\%) *$ \\
\hline Malassezia sp & 63,3 \\
cocos Gram + & 56,6 \\
bastonetes Gram + & 43,3 \\
bastonetes Gram - & 26,6 \\
\hline
\end{tabular}

*Valores superiores a $100 \%$ pois foram considerados tanto os microrganismos isoladamente quantas associações entre eles. pesquisados com o uso dos corantes de Papanicolaou e Rosenfeld (Figura 6). Os percentuais de leucócitos observados encontram-se expostos na Tabela 3. Análises citológicas conduzidas em espécimes obtidos de condutos auditivos hígidos demonstraram ausência destes tipos celulares.

Os métodos de Papanicolaou e Rosenfeld permitiram ainda a detecção de eritrócitos em secreções de ouvidos nos quais foram encontradas ulcerações, localizadas no epitélio meatal (Tabela 4). Amostras de condutos auditivos sãos, não exibiram hemácias.

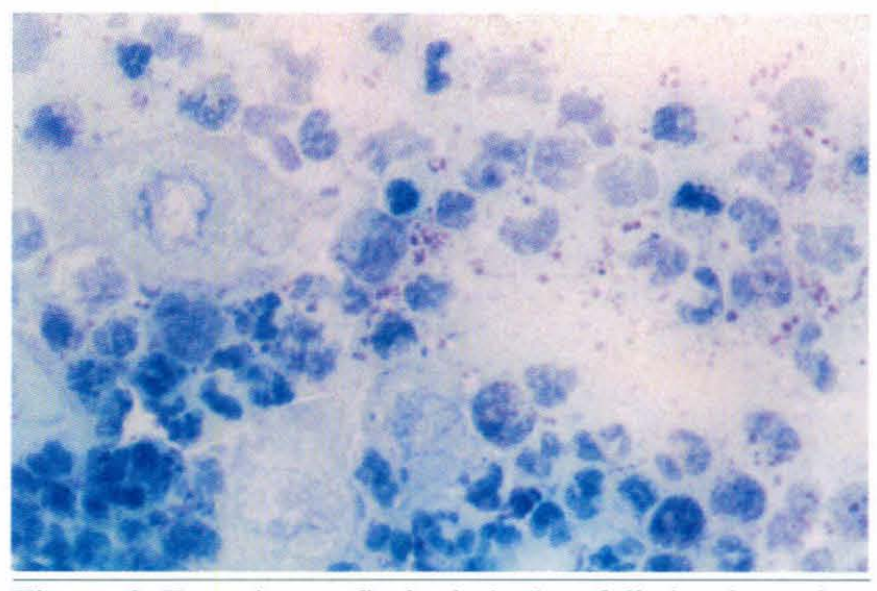

Figura 6 - Fotomicrografia de citologia esfoliativa de conduto auditivo externo de cão com otite. Observar exsudato misto e fagocitose de bactérias. Rosenfeld (1000x)

Tabela 2 - Percentual de extensões oriundas de cães com otite externa, segundo a presença de células epiteliais coradas através das técnicas de Papanicolaou e Rosenfeld. São Paulo, SP, 2004

\begin{tabular}{|c|c|c|c|c|}
\hline \multirow{2}{*}{ Células epiteliais } & \multicolumn{2}{|c|}{ Papanicolaou } & \multicolumn{2}{|c|}{ Rosenfeld } \\
\hline & $\mathrm{N}^{2}$ absoluto & $(\%)$ & No absoluto & $(\%)$ \\
\hline Superficiais & 28 & 93,3 & 28 & 93,3 \\
\hline Superficiais / parabasais & - & - & 1 & 3,3 \\
\hline Ausentes & 2 & 6,6 & 1 & 3,3 \\
\hline Total & 30 & 100,0 & 30 & 100,0 \\
\hline
\end{tabular}


Tabela 3 - Percentual de extensões oriundas de cães com otite externa, segundo a presença de células inflamatórias coradas através das técnicas de Papanicolaou e Rosenfeld. São Paulo, SP, 2004

\begin{tabular}{|c|c|c|c|c|}
\hline \multirow{2}{*}{ Células inflamatórias } & \multicolumn{2}{|c|}{ Papanicolaou } & \multicolumn{2}{|c|}{ Rosenfeld } \\
\hline & $\mathrm{N}^{2}$ absoluto & $(\%)$ & $\mathrm{N}^{2}$ absoluto & $(\%)$ \\
\hline Neutrófilos & 15 & 50,0 & 12 & 40,0 \\
\hline Neutrófilos /mononucleares & - & - & 3 & 10,0 \\
\hline Ausentes & 15 & 50,0 & 15 & 50,0 \\
\hline Total & 30 & 100,0 & 30 & 100,0 \\
\hline
\end{tabular}

Tabela 4 - Percentual de extensões oriundas de cães com otite externa, segundo a presença de hemácias coradas através das técnicas de Papanicolaou e Rosenfeld. São Paulo, SP, 2004

\begin{tabular}{llcccc}
\hline & Eritrócitos & \multicolumn{2}{c}{ Papanicolaou } & & Rosenfeld \\
\cline { 2 - 5 } & & $\mathrm{N}$ absoluto & $(\%)$ & No absoluto & $(\%)$ \\
\hline Presentes & 9 & 30,0 & 3 & 10,0 \\
Ausentes & 21 & 70,0 & 27 & 90,0 \\
\hline Total & 30 & $\mathbf{1 0 0 , 0}$ & 30 & 100,0 \\
\hline
\end{tabular}

\section{Discussão}

Embora a patogênese da otite em cães ainda não esteja completamente elucidada, aceita-se como verídica a ação de fatores predisponentes em seu desenvolvimento, os quais podem promover desequilíbrio microambiental no conduto auditivo, determinando a multiplicação desordenada de microrganismos comensais existentes na região ${ }^{8,9}$. O presente estudo investigou a possível influência destes elementos na fisiopatogenia da enfermidade abordada.

Foram avaliados 30 cães com otite externa, dentre os quais $60 \%(n=18)$ tinham raça definida. Considerando-se estes indivíduos, houve predomínio de Poodles, $21 \%(n=6)$ e de Pastores-Alemães, $21 \%$ $(n=6)$, dado concordante com os obtidos na literatura consultada ${ }^{10-16}$. Esta pesquisa demonstrou quantidade superior de fêmeas afetadas por otite $(60 \%)$. Entretanto, ainda não há consenso definitivo sobre a existência de predisposição sexual para o distúrbio ${ }^{4,12,13,17}$. Grande parcela dos pacientes afetados apresentava idade igual ou superior a quatro anos (74\%), faixa etária de maior incidência da moléstia também anteriormente documentada ${ }^{4,12,14}$.

O presente trabalho detectou que $60 \%$ dos animais do grupo Otite apresentavam pêlos curtos, embora investigações anteriores tenham correlacionado a abundância de pêlos no interior do conduto auditivo de algumas raças com pelagem longa, à ocorrência significativamente maior da moléstia em cães com esta característica ${ }^{2,10,16,18}$. Todavia, dentre os cães otopatas com raça definida que foram pesquisados, ressalta-se o alto percentual de Poodles verificado neste estudo. 
Todos os exemplares sem raça definida assim como a maior parte dos indivíduos de raça pura com otite exibiam orelhas pendulares $(80 \%)$, reafirmando a relação direta entre anatomia dos pavilhões auriculares e a predisposição ao desenvolvimento de afecção ótica $^{4,8,10,16}$. Pavilhões auriculares pendulares limitam a ventilação no interior dos condutos, determinando aumento na umidade regional com conseqüente maceração epitelial ${ }^{8.9}$.

Análises microscópicas de secreções óticas realizadas com a técnica de Gram mostraram-se eficientes na busca por microrganismos relacionados à otite externa, tal como previamente registrado ${ }^{17,19-24}$. O referido princípio de coloração permitiu a observação da morfologia e arranjo de agentes microbianos e a classificação de bactérias em Gram positivas e Gram negativas. Tais informações auxiliam na seleção de antibióticos com maior propriedade, ampliando as chances de instituírem-se protocolos terapêuticos mais precisos e adequados, mesmo na ausência dos testes de cultivo e sensibilidade 9 . Os microrganismos bacterianos constatados em maior freqüência nos casos de otite externa foram cocos Gram positivos, provavelmente Staphylococcus sp e/ou Streptococcus $\mathrm{sp}^{9,5,25,26}$. Algumas extensões derivadas de ouvidos severamente enfermos demonstraram existência de bastonetes Gram negativos. Pesquisas anteriores indicaram a importância da evidenciação destas bactérias em condutos auditivos enfermos, reconhecidamente representadas pelos gêneros Pseudomonas e/ou Proteus ${ }^{9,25-27}$.

$\mathrm{O}$ método de Gram prestou-se também à detecção de leveduras com brotamento único em base larga (Malassezia sp), reafirmando a utilidade do exame direto de secreções óticas na observação dos referidos microrganismos ${ }^{59,25,29}$. Malassezia sp foi o agente microbiano mais encontrado nos espécimes advindos de cães com otite $(63,3 \%)$; esteve presente como microrganismo único em $43,3 \%$ das amostras e associado a bactérias em $20,0 \%$ dos casos, caracterizando-se como principal patógeno envolvido em otopatias caninas, tal como averiguado na literatura pertinente ${ }^{9,17,28}$. Embora o habitat desta levedura não seja perfeitamente conhecido, considera-se normal o encontro da mesma em pequena quantidade no conduto auditivo externo de cães livres de moléstia ótica ${ }^{4,69}$. Cabe ressaltar que no grupo-controle, a Malassezia sp ocorreu de manei- ra bem menos consistente do que a verificada nos preparados de ouvidos enfermos.

Em relação à presença de células epiteliais, estas foram detectadas com auxílio das técnicas de Papanicolaou e Rosenfeld em, respectivamente, 93,3\% e 96,6\% de espécimes produzidos a partir de condutos doentes. Análises citológicas preliminares conduzidas em amostras oriundas de cães otopatas revelaram achados similares ${ }^{59,26}$. Nos materiais advindos de orelhas hígidas, apenas raras células epiteliais foram localizadas, assim como previamente documentado ${ }^{6}$.

A presença de exsudato séptico no ouvido enfermo só pode ser confirmada mediante constatação citológica de leucócitos degenerados e/ou em atividade fagocítica ${ }^{4,8,30,31}$. Avaliações procedidas em espécimes de material ótico, segundo a metodologia empregada, forneceram dados concordantes com esta informação. Foram detectados neutrófilos em $50 \%$ e $40 \%$, respectivamente, das extensões coradas por Papanicolaou e Rosenfeld, e neutrófilos e células inflamatórias mononucleares em $10 \%$ das amostras coradas por Rosenfeld. Os tipos celulares encontrados auxiliam na caracterização da natureza e do tempo de existência do evento inflamatório oferecido em resposta à ação dos agentes da injúria ${ }^{6}$. Leucócitos não foram observados nos materiais derivados de ouvidos sãos, reafirmando dados também postulados por Chickering ${ }^{6}$.

Foram verificados eritrócitos associados a leucócitos contendo microrganismos fagocitados em casos severos de enfermidade ótica, indicando a natureza piossangüinolenta destes exsudatos, usualmente decorrentes da ação ulcerogênica de bactérias Gram negativas sobre o epitélio meatal ${ }^{6}$. Cabe ressaltar que hemácias não foram evidenciadas nas extensões provenientes de condutos auditivos hígidos.

Associar os dados colhidos na anamnese e no exame físico às informações fornecidas pelo estudo microscópico de secreções óticas produz resultados satisfatórios na instituição de protocolos terapêuticos mais precisos e eficazes ${ }^{4,6}$.

\section{Conclusões}

- No tocante aos fatores predisponentes investigados, grande parcela dos cães com otite externa possuía raça definida, verificando-se maior ocorrência da 
moléstia em Poodles e Pastores-Alemães. A maioria dos animais afetados eram fêmeas, com idade igual ou superior a quatro anos, pelagem curta e orelhas pendulares;

- As técnicas de Papanicolaou e Rosenfeld prestaram-se à observação de células epiteliais, inflamatórias e eritrócitos, auxiliando na caracterização da presença de eventos inflamatórios e hemorrágicos, decorrentes de injúrias oferecidas aos tecidos de revestimento do conduto auditivo externo;
- Leveduras com brotamento único em base larga (Malassezia sp) foram os microrganismos mais freqüentes nos casos de otite;

- As análises citológicas mostraram-se facilmente executáveis, pouco onerosas e rápidas, sendo indicadas em todos os casos de otite externa na busca de elementos relacionados à ocorrência da enfermidade estudada. O emprego da citologia diminui as dúvidas quanto às causas do processo, orientando a adoção de condutas terapêuticas mais precisas e adequadas.

\section{Abstract}

Objective: To study dogs bearing otitis externa, objectifying the detection of predisposing factors and microorganisms involved in the etiopathogenesis of this disease. Material and Method: Forty animals (30 of them had otitis externa and 10 without the disease) from the "Serviço de Clínica Médica da Faculdade de Medicina Veterinária da Universidade Paulista", (Medical Clinic Service from the Veterinary Hospital of Paulista Veterinary Medicine University) São Paulo, SP, Brazil, were submitted to prior physical otological examination. The ear secretion samples were obtained from external ear canal using gynecological brushes, submitted to posterior cytological analysis with the help of three different coloration techniques. Results: Among the patients with otitis, $60 \%$ was pure breed dogs, $60 \%$ female, $74 \%$ aged four years old onward, $60 \%$ had short-hair coat and $80 \%$ with pendulous ears. Gram method was shown as the most effective in the research of bacteria and fungus, and Papanicolaou and Rosenfeld techniques were the most adequate to the observation of ephitelial and inflammatory cells and erythrocytes. The most common microorganism found in the extensions produced by the affected ears was Malassezia sp (63.3\%). Conclusions: The results indicate that data collected from anamnesis and physical examination, jointly with information provided by the cytological study of ear secretions are efficient in characterizing the elements incriminated in the etiopathogenesis of canine otitis.

Keywords: Otitis externa, etiology. Clinical diagnosis. Ear canal, cytology. Cytological techniques. Dogs.

\section{Resumen}

Objetivo: Estudiar perros portadores de otitis externa, con la finalidad de detectar factores de predisposición y microorganismos involucrados en la etiopatogénesis de esa afección. Material y Método: Cuarenta animales (30 con otitis externa y 10 sin la enfermedad) provenientes del Servicio de Clínica Médica del Hospital Veterinário de la Faculdade de Medicina Veterinária de la Universidade Paulista, São Paulo, SP, Brasil, fueron sometidos a examen otológico físico previo. Muestras de secreción óptica fueron retiradas del conducto auditivo externo con cepillos ginecológicos, realizándose posterior análisis citológico en esos materiales, con 
auxilio de tres técnicas distintas de coloración. Resultados: Entre los pacientes con otitis se encontró $60 \%$ de perros de raza definida, $60 \%$ de hembras, $74 \%$ con edad igual o superior a cuatro años, $60 \%$ con pelaje corto y $80 \%$ con orejas pendulares. El método de Gram se mostró eficaz en la pesquisa de bacterias y hongos, y las técnicas de Papanicolaou y Rosenfeld más adecuadas para la observación de células epiteliales, inflamatorias y eritrocitos. El microorganismo más verificado en las extensiones producidas a partir de oídos enfermos fue Malassezia sp (63,3\%). Conclusiones: Los resultados indican que datos recogidos en la anamnesis y examen físico, aliados a las informaciones suministradas por el estudio citológico de secreciones ópticas son eficientes en la caracterización de elementos incriminados en la etiopatogénesis de la otitis canina.

Palabras-clave: Otitis externa, etiología. Diagnóstico clínico. Conductos auditivos, citología. Técnicas citológicas. Perros.

\section{Referências}

1. AUGUST, J. R. Otitis externa: a disease of multifactorial etiology. The Veterinary Clinics of North America: Small Animal Practice, v. 18, p. 731-742, 1988.

2. BRUYETTE, D. S.; LORENZ, M. D. Otitis externa and otitis media: diagnostic and medical aspects. Seminars in Veterinary Medicine and Surgery: Small Animal, v. 8, p. 3-9, 1993.

3. CARLOTTI, D. N. Diagnosis and medical treatment of otitis externa in dogs and cats. Journal of Small Animal Practice, v. 32, p. 394-400, 1991.

4. CASTELLANO, M. C. Evaluacion clinica del perro com otitis externa. Veterinaria Argentina, v. 12, p. 332-337, 1995.

5. Mc KEEVER, P. J. Otitis externa. Compendium on Continuing Education for the Practicing Veterinarian, v. 18, p. 759-772, 1996.

6. CHICKERING, W. R. Cytologic evaluation of otic exudates. The Veterinary Clinics of North America: Small Animal Practice, v. 18, p. 773-782, 1988.

7. NOXON, J. O. Otite externa. In: BICHARD, S. J.; SHERDING, R. G. Clínica de pequenos animais. São Paulo: Rocca, 1998. p. 424-429.
8. COWELL, R. L. et al. The external ear canal. In: COWELL, R.L.; TYLER, R. D. Diagnostic cytology of the dog and cat. Goleta: American Veterinary Publications, 1989. p. 77-81.

9. KOWALSKI, J. J. The microbial environment of the ear canal in health and disease. The Veterinary Clinics of North America: Small Animal Practice, v. 18 , p. $743-754,1988$.

10. BABA, E. et al. Incidence of otitis externa in dogs and cats in Japan. The Veterinary Record, v. 108, p. 393-395, 1981.

11. FERREIRO, L. et al. Flora bacteriana isolada de cães com otite externa na grande Porto Alegre, RS Brasil, no período de 1984 - 1986. Arquivos da Faculdade de Veterinária da Universidade Federal do Rio Grande do Sul, v. 14, p. 35-44, 1986.

12. GRONO, L. R. Observations on the incidence of otitis externa in the dog. Australian Veterinary Journal, v. 45, p. 417-419, 1969.

13. HAYES JR., H. M. et al. Effects of ear type and weather on the hospital prevalence of canine otitis externa. Research in Veterinary Science, v. 42, p. 294-298, 1987.

14. MAGALHÃES, M. J. et al. Otite externa em cães atendidos no Hospital Veterinário da Universidade 
Federal de Minas Gerais: etiologia, frequiência e sensibilidade antibiótica. Arquivo Brasileiro de Medicina Veterinária e Zootecnia, v. 37, p. 333-341, 1985.

15. MEGID, J. et al. Otite canina: etiologia, sensibilidade antibiótica e susceptibilidade animal. Semina, v. 11 , p. $45-48,1990$.

16. RYCROFT, A.K.; SABEN, H. S. A clinical study of otitis externa in the dog. Canadian Veterinary Journal, v. 18, p. 64-70, 1977.

17. COLE, L. K. et al. Microbial flora and antimicrobial susceptibility patterns of isolated pathogens from the horizontal ear canal and middle ear in dogs with otitis media. Journal of the American Veterinary Medical Association, v. 212, p. 534-538, 1998.

18. HAMMOND, D. L. et al. Histological effects of a chemical depilatory on the auditory canal of dogs. Journal of the American Animal Hospital Association, v. 26, n. 5, p. 551-554, 1990.

19. CHESTER, D. K. Medical management of otitis externa. The Veterinary Clinics of North America: Small Animal Practice, v. 18, p. 799-812, 1988.

20. GRIFFIN, C. E. Infecciones tegumentarias. In: GREENE, C. E. Enfermedades infecciosas: perros y gatos. Mexico, DF: Nueva Editorial Interamericana, 1993. p. 78-89.

21. MANSFIELD, P. D. Preventive ear care for dogs and cats. The Veterinary Clinics of North America: Small Animal Practice, v. 18, p. 845-858, 1988.

22. ROSSER JR., E. J. Evaluation of the patient with otitis externa. The Veterinary Clinics of North America: Small Animal Practice, v. 18, p. 765-772, 1988.
23. ROSYCHUK, R. A. W. Management of otitis externa. The Veterinary Clinics of North America: Small Animal Practice, v. 24, p. 921-952, 1994.

24. WOODY, B. J.; FOX, S. M. Otitis externa: seeing past the signs to discover the underlying cause. Veterinary Medicine: Small Animal Clinician, v. 6 , p. 616-24, 1986.

25. Mc KEEVER, P. J.; TORRES, S. M. F. Ear disease and its management. The Veterinary Clinics of North America: Small Animal Practice, v. 27, p. 1523-1536, 1997.

26. SCOTT, D. W. et al. Doenças das pálpebras, unhas, sacos anais e condutos auditivos. In:

Dermatologia de pequenos animais. Rio de Janeiro: Interlivros, 1996. p. 894-925.

27. DICKSON, D. B.; LOVE, D. N. Bacteriology of the horizontal ear canal of dogs. Journal of Small Animal Practice, v. 24, p. 413-421, 1983.

28. DWORECKA-KASZAK, B. et al. Applicability of microscopic examination and isolation of Malassezia pachydermatis (Pityrosporum pachydermatis) on microbial media to diagnosis of otitis externa. Archivum Veterinarium Polonicum, v. 35, p. 159167, 1995.

29. Mc KEEVER, P. J.; TORRES, S. M. F. Otitis externa. Part 1. The ear and predisposing factors to otitis externa. Companion Animal Practice, v. 2, p. 7-12, 1988.

30. KISS, G. et al. New combination for the therapy of canine otitis externa. I. Microbiology of otitis externa. Journal of Small Animal Practice, v. 38, p. 51-56, 1997.

31. TILLEY, L. P. et al. The $\mathbf{5}$ minutes veterinary consult: canine and feline. Baltimore: Willians \& Wilkins, 1997. 1.287p. 